\title{
Profissão e corporação: limites éticos da atuação do advogado
}

MARCELO PEREIRA DE MELLO" MÁRCIA REGINA C. BARROSO"

\section{Resumo}

Este trabalho faz uma análise da atuação do Tribunal de Ética e Disciplina da OAB-RJ a partir de dois eixos: o primeiro acompanha uma análise qualitativa das infrações mais frequentes cometidas pelos advogados decorrentes de suas atividades profissionais e perpassa uma análise da administração das punições pelos membros do Tribunal. O segundo eixo persegue a avaliação deste Tribunal na estrutura organizacional interna da OAB e seu papel na legitimação da participação política da entidade. Sendo assim, analisamos a difícil tarefa de equilibrar-se entre as suas atividades de entidade de representação classista e o seu papel político.

Palavras-chave: Sociologia das profissões. Ética profissional. Advogados. Tribunal de Ética.

\footnotetext{
* Professor Associado do Departamento de Sociologia da Universidade Federal Fluminense (UFF). Subcoordenador do Programa de Pós-Graduação em Sociologia e Direito PPGSD/UFF. E-mail: mpmello@unisys.com.br

** Mestranda do Programa de Pós-Graduação em Sociologia e Direito da Universidade Federal Fluminense (PPGSD-UFF). E-mail: marciajose@ig.com.br
} 


\section{Introdução}

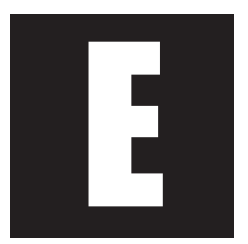

ste artigo se propõe a fazer uma reflexão sobre a atuação do Tribunal de Ética e Disciplina da OAB, seção Rio de Janeiro, a partir de dois eixos, os quais acreditamos sustentar a sua posição institucional: o primeiro acompanha uma análise qualitativa das infrações mais frequentes cometidas pelos advogados decorrentes de suas atividades profissionais e perpassa uma análise da administração das punições pelos membros do Tribunal. Esse eixo sustenta a posição da entidade junto aos advogados na defesa de seus interesses corporativos e profissionais. O segundo eixo persegue a avaliação da posição do Tribunal de Ética e Disciplina da OAB tanto na estrutura organizacional interna quanto o seu papel na legitimação da participação política da entidade.

Para cumprirmos nosso objetivo, iniciamos nosso trabalho fazendo um breve comentário a respeito do Código de Ética da OAB e suas funções de fixação de um padrão de conduta pessoal e disciplinar dos advogados. Com base em entrevistas realizadas e dados levantados junto à instituição, fazemos a análise de alguns indicadores de seu desempenho e objetivos institucionais. Em um segundo momento, analisamos a difícil tarefa do Tribunal de Ética e Disciplina da OAB-RJ de equilibrar-se entre as atividades de representação classista da entidade, na qual se destaca o monopólio do credenciamento profissional dos advogados e o seu papel político: ou mais detalhadamente, entre as funções disciplinadoras e fiscalizadoras da atividade profissional dos advogados e como reserva moral da entidade legitimadora da sua atuação política. 


\section{Ética profissional e o Código de Ética da OAB}

Todas as profissões têm os seus códigos éticos, e, decerto, estabelecem regras, mesmo que elas não estejam escritas nem formalizadas em um Código específico, que visam a estabelecer normas de conduta e parâmetros para o comportamento profissional. Para os profissionais da área do Direito, esses códigos éticos assumem um relevo especial, dadas as características singulares da atuação dos advogados, e pelo tipo de serviços que oferecem à sua clientela vinculados ao forte simbolismo do valor supremo que ajudam a realizar: a justiça. Como nos indica Barbosa (2002, p. 297), entre as pessoas comuns uma violação do preceito ético pode acarretar apenas um repúdio, ou uma desaprovação social. Porém, entre os advogados, a violação de determinados deveres éticos está sujeita às sanções do seu Estatuto, onde tais normas deixam de ser de cunho puramente ético para ser normas jurídicas de direito administrativo, e implicando, portanto, em sanções administrativas. Além disso, como observa um funcionário do Tribunal de Ética entrevistado, após a finalização do processo a pessoa lesada pode entrar na justiça reclamando por dano moral e as reparações devidas, anexando à ação a decisão do Tribunal de Ética.

Essas informações nos suscitam uma reflexão inicial: por que o Código de Ética e Disciplina da OAB possui tantas exigências para que o advogado tenha um padrão de probidade e de honradez no seu comportamento social e profissional? Um argumento que tem sido amplamente divulgado se refere ao fato de os advogados exercerem uma atividade fundamental para o interesse coletivo e essencial para a administração da justiça, como informa Nalini (2000, p. 29). Nesse sentido, o exercício da Advocacia se encontra de forma estreitamente vinculada ao fim da própria instituição Judiciária. 
Ainda segundo Nalini (2000, p. 28), antes mesmo da criação da $\mathrm{OAB}^{1}$, já havia um primeiro código de Ética profissional dos Advogados produzido pelo Instituto dos Advogados de São Paulo (IASP), o primeiro em toda a América do Sul, datado de 1921. O código, entretanto, se restringia a conselhos de natureza moral e não tinha um caráter punitivo. Com o surgimento da $\mathrm{OAB}$, criou-se um estatuto de ética profissional com uma detalhada normatização, datado de 1934, conforme aponta Lôbo (2009, p. 165).

O atual Código de Ética e Disciplina da OAB, instituído pela Lei no 8.906 de 1994, funciona como um instrumento normativo e como uma síntese dos deveres dos advogados que, conforme já comentamos, são profissionais considerados essenciais à administração da Justiça. Uma característica interessante desse novo Código de Ética, como nos acrescenta Lôbo (2009:179), é que ele não só trata dos deveres éticos, como também estabelece os procedimentos disciplinares necessários à sua plena efetividade.

O órgão responsável pela instauração dos processos disciplinares é o Tribunal de Ética e Disciplina da OAB (TED) que, através do Conselho Seccional, pode instaurar processos por conta própria, ou pode dar consequência às representações de clientes, de advogados, de juízes, etc. (Alemão, 2009, p. 200).

Segundo Coccaro (2009, p. 204), há na OAB dois tipos de processos: a) os que têm como meta a apuração da conduta do advogado e, se preciso for, determinar algum tipo de sanção e constituem, portanto, os processos disciplinares; b) os outros seriam aqueles denominados de administrativos por tratarem de questões como inscrição e transferências, registro de sociedade de advogados, pagamento de anuidades e outros.

Quanto às sanções previstas no art. 35 do Estatuto/1994, estas podem se apresentar sob quatro formas: censura, suspensão, exclusão e multa. Do ponto de vista da administração política das punições, a cen-

1 Criada com o Decreto no 19.408, de 18 de novembro de 1930. 
sura tem um menor potencial punitivo, seguidos pela multa, suspensão e exclusão profissional. E os casos considerados com um maior poder ofensivo na opinião de um conselheiro entrevistado, e que são normalmente tratados com mais rigor, são aqueles em que o advogado recebe dinheiro em ações vitoriosas e não repassa o devido valor ao cliente.

Com respeito aos procedimentos dos Tribunais de Ética no país, o órgão federal da $\mathrm{OAB}$ dá as diretrizes para que se tenha uma padronização. Entretanto, o funcionamento desses tribunais apresenta algumas diferenças regionais. Na prática, cada Tribunal tem certa margem de autonomia para a organização desses julgamentos e para a metodologia de seus procedimentos internos. Essa organização também pode ser alterada a partir da entrada de novos membros que são escolhidos a cada três anos. Melhor dizendo, o presidente da OAB é eleito a cada três anos, e faz a indicação do presidente do Tribunal de Ética. Assim, o próprio processo eleitoral afeta de maneira direta o andamento dos processos na medida em que os membros das turmas de julgamento são mudados de acordo com o resultado das eleições e, indiretamente, também, porque não é raro que os membros do Tribunal se envolvam com o processo eleitoral, o que também altera o ritmo do andamento dos processos. Isso ocorre usualmente entre os meses de novembro a janeiro nos anos de eleição.

Na seção Rio de Janeiro da OAB, são cinco as turmas de julgamento no Tribunal, onde cada uma delas conta com um presidente que é conseIheiro da instituição. As turmas de julgamento são compostas em média por 12 membros cada uma. O trabalho é voluntário e não remunerado, e cada membro das turmas comparece a uma média de quatro sessões mensais. Há sessões quase todos os dias realizadas alternadamente pelas diferentes turmas. Segundo funcionários entrevistados, entre a fase de solicitação de abertura do processo pelo Tribunal e o recebimento do comunicado pelo advogado alvo da representação, o tempo médio é de um mês. 
Para nossos estudos, fizemos um levantamento exaustivo do conjunto de processos entre os anos de 1996 e 2008, em um total de 15.453 processos. Para efeitos de uma análise qualitativa do fluxo processual entre os tipos de infrações, punições e tempo de julgamento, analisamos individualmente todos os processos julgados pelo Tribunal de Ética nos anos ponta: 1996 e 2008, em um total de 1.659 processos. Objetivamos assim verificar as alterações no longo prazo quanto ao tipo de infrações incidentes e à média do tempo dos julgamentos.

Atualmente, na OAB-RJ, estão em andamento cerca de sete mil processos por infrações éticas e administrativas. Embora possa impressionar pela quantidade, o número de processos, contudo, não parece ser tão expressivo quando cotejado com o número total de advogados registrados atualmente na seccional do Rio de Janeiro: $133.174^{2}$. Segundo comentário de um funcionário com experiência de dez anos na $\mathrm{OAB}$, o número de pedidos para abertura desses processos tem aumentado com o passar dos anos, o que ele atribui a um aumento do número de profissionais e a pulverização desses por um número crescente de pequenos escritórios. No entanto, em termos relativos esse aumento é menos que proporcional ao número de novos advogados inseridos no mercado pelos novos cursos jurídicos e credenciados pela prova da OAB-RJ ${ }^{3}$. Também, chama-nos a atenção que, a despeito do número de processos abertos pelo TED ter crescido, ainda que em proporção pequena em relação ao aumento dos

2 Informações obtidas pela OAB federal - site: www.oab.org.br/relatorioAdvOAB.asp. Atualizado em 16-02-2011.

3 De acordo com Meirelles, a OAB estimava no ano de 2002 que existam mais de 450 cursos jurídicos funcionando no Brasil, quase a metade deles criados entre 1997 e 2001, (portal Consultor Jurídico, extraído em 25/01/02 - <http://cf6.uol.com.br/consultor/view. $\mathrm{cfm}$ ? numero $=8501 \& \mathrm{ad}=\mathrm{b}>$ ). Cit.in: Meirelles, Delton Soares. Tese de Mestrado. Alemão (2009) afirma que em 2003 havia mais de 700 cursos de Direito no Brasil e que, em 2007, esse 
profissionais no mercado, o número de processos efetivamente julgados por ano variou muito pouco, tendo até mesmo regredido em alguns anos. Vejam-se os dados da Tabela 1 a seguir:

Tabela 1 - Total de processos julgados por ano

\begin{tabular}{|c|c}
\hline Ano & Total de Processos \\
\hline 1996 & 844 \\
\hline 1997 & 1079 \\
1998 & 1010 \\
\hline 2000 & 828 \\
2001 & 1153 \\
2002 & 1663 \\
2003 & 1863 \\
2004 & 1480 \\
2005 & 1998 \\
2006 & 883 \\
\hline 2007 & 1180 \\
\hline 2008 & 657 \\
\hline
\end{tabular}

Fonte: Departamento de Pesquisa da OAB - RJ: Ementário Digital

número já ascendia para 1.049. Na verdade, nem todo bacharel em Direito exerce a profissão de advogado. Muitos, inclusive, não conseguem passar no exame da OAB que os credencia para o exercício profissional. No entanto, é fato que o número de advogados credenciados tem crescido em ritmo muito maior que o crescimento do número de processos abertos no TED. Em 2003, por exemplo, apenas na seção Rio de Janeiro da OAB, havia o registro de 89.829 advogados credenciados. 
No que se refere ao tempo médio de duração desses processos, outra impressão de um funcionário do TED colhida em entrevista é a de que os prazos de julgamento têm diminuído nos últimos anos em função, segundo afirma, da utilização progressiva dos meios informáticos pela instituição. Nas suas palavras: "o que antes levava em torno de três anos para ser julgado, após essa alteração passou a durar em média de sete meses a um ano e meio". Esta impressão não está respaldada, também, pelos dados recolhidos. Conforme os dados da Tabela 2, a seguir, o que observamos é que, considerados os anos de 1996 e 2008, situados na extremidade do lapso temporal dos dados obtidos, o tempo médio para o total de processos julgados é rigorosamente o mesmo: 3 anos e cinco meses. Se diminuiu em alguns tipos de processos como nos casos de "desídia", passando de uma média de 3 anos e sete meses em 1996 para 1 ano e nove meses em 2008, para o caso algo similar de "inépcia profissional" aumentou o tempo de julgamento de 2 anos e três meses para 3 anos e três meses. Na maioria dos outros casos, o tempo do processo permaneceu com variações muito pequenas para mais ou para menos ou até mesmo não variou. 
Tabela 2

\begin{tabular}{|c|c|c|}
\hline Tempo médio de duração do processo por assunto/ anos & 1996 & 2008 \\
\hline Abandono de Causa & 3 & 2 \\
\hline Advogado empregado & 1,6 & - \\
\hline Advogar Contra Lei & 2 & 4 \\
\hline Anuidade e inadimplência & 3,1 & 11,8 \\
\hline Arquivamento e Improcedência da Representação & 2,8 & 2,8 \\
\hline Assinatura em Escrito Indevida & 3 & 3 \\
\hline Captação de Causas e publicidade na advocacia & 1,8 & 2,5 \\
\hline Competência & 1,1 & 3,7 \\
\hline Conduta Incompatível & 3,2 & 2,6 \\
\hline Consulta & 0,6 & 0,5 \\
\hline Desídia & 3,7 & 1,9 \\
\hline Desobediência à OAB & 3,7 & 3,3 \\
\hline Deturpar o Teor de Dispositivo de Lei & 3 & 1,3 \\
\hline Dever de Urbanidade & 2,6 & 3,2 \\
\hline Entendimento com Parte Adversa sem Autorização & 3,5 & 3,8 \\
\hline Estagiário & 1,2 & 2 \\
\hline Exclusão & 7 & - \\
\hline Exercício llegal da Profissão & 3,9 & 2,6 \\
\hline Extravio de Autos & 3 & 5 \\
\hline Falsa Prova de Requisito de Inscrição & 4 & 3 \\
\hline Honorários & 2 & 4 \\
\hline Impedimento & 4,8 & 3 \\
\hline Imputação Indevida de Crime & 5 & 1,5 \\
\hline Inépcia Profissional & 2,3 & 3,3 \\
\hline Inscrição Principal & 10,4 & 7,4 \\
\hline Licenciamento da Advocacia & - & 12,4 \\
\hline Mandato & 7 & 2,8 \\
\hline Patrocínio Infiel & 3,3 & 1 \\
\hline
\end{tabular}


Continuação...

\begin{tabular}{|l|c|c|}
\hline Pedido de Revisão & 2,8 & 5,9 \\
\hline Prejudicar o Cliente por Culpa Grave & 2,6 & 2,6 \\
\hline Prerrogativas do Advogado & 0,9 & 1,6 \\
\hline Prescrição & 5,3 & 6,7 \\
\hline Processo Disciplinar & 2,2 & 2,5 \\
\hline Reabilitação & 11,4 & - \\
\hline Recebimento de Valores sem Autorização do Constituinte & 5 & 3,3 \\
\hline Recurso & 4,5 & 3,8 \\
\hline Recusa de Prestação de Contas & 3,3 & 2,9 \\
\hline Retenção Abusiva de Autos & 2,9 & 2,3 \\
\hline Sociedade de Advogados Ilícita & 2,3 & - \\
\hline Violar Sigilo Profissional & - & 3,3 \\
Tempo médio total de duração do processo & $\mathbf{3 , 5}$ & $\mathbf{3 , 5}$ \\
\hline
\end{tabular}

Fonte: Departamento de Pesquisa da OAB - RJ: Ementário Digital

A questão também da "inscrição principal", que se refere aos pedidos de inclusão dos advogados aos quadros da Ordem, acaba por ter uma inserção relevante dentre os assuntos tratados por este tribunal. Destacamos que, além de ser um assunto muito recorrente, ele também tem exigido muitos anos, em média, para a sua resolução (conforme podemos observar na Tabela 2). No ano de 1996, tal assunto levou o tempo médio de 10 anos e quatro meses, e em 2008, 7 anos e quatro meses. Tais informações demonstram a complexidade da questão e também a grande importância que essa entidade profissional dá para a problemática do acesso aos seus quadros.

Somadas as informações contidas nas Tabelas 1 e 2, ou seja, o número absoluto de processos julgados e o tempo médio dos julgamentos,vê-se que a capacidade de julgamentos do Tribunal de Ética tem se mantido em níveis estáveis nos últimos 12 anos. Seu padrão de rendimento (ou produtividade), também, pouco se alterou. Essa estabilidade,como vimos, 
não se coaduna com o expressivo aumento do número de profissionais credenciados no mesmo período.

De toda sorte, esse fenômeno não é estranho do ponto de vista sociológico. O que é quase um consenso entre os sociólogos é que os dados produzidos pelas organizações refletem muito mais as suas próprias características organizacionais, seus meios procedimentais e sua "lógicaem-uso", na expressão de Cicourel (1968), do que os resultados obtidos segundo critérios estritamente científicos e racionais.

\section{Os processos do Tribunal de Ética e Disciplina da OAB-RJ}

Uma primeira e elementar observação a se fazer sobre os dados apurados é que eles representam, naturalmente, apenas os casos levados ao conhecimento e protocolados no Tribunal. Isso nos leva a fazer algumas ressalvas quanto à exatidão da representação em termos absolutos (quantidade) e relativos (incidência) das infrações de caráter disciplinar e administrativas efetivamente cometidas pelos advogados e aquelas instauradas pelo Tribunal de Ética. Os dados da Tabela 3 mostram a evolução anual da quantidade de reclamações organizadas por tipos. Como dissemos, esses números referem-se apenas aos processos abertos no TED, e, digamos, a muito provável subnotificação das infrações éticas dos advogados não atinge de igual modo todos os tipos de infração tipificados pelo Código de Ética dos Advogados. É de se supor, por exemplo, que as queixas e reclamações de clientes prejudicados pelos serviços prestados pelos advogados nos casos de "desídia", "inépcia profissional" e "honorários", por exemplo, sejam em número muito maior que as efetivamente protocoladas no Tribunal, dado que nem todas as pessoas leigas sabem que podem formalizar uma queixa na OAB contra os advogados. Outra infração que nos parece subnotificada diz respeito àquelas relacionadas à Publicidade da Advocacia e de Serviços Profissionais. Seguramente, não estão sendo consideradas nem levadas ao Tribunal as inúmeras formas de 
publicidade de advogados que se aproveitam do potencial de causas que atingem um grande número de pessoas e que estão relacionadas às indenizações trabalhistas, aquelas relativas a perdas oriundas por medidas geradas no bojo de políticas governamentais, os chamados "pacotes econômicos", por exemplo, as infrações de trânsito e inúmeras outras. Também, as modernas formas de propaganda e divulgação subliminar de serviços advocatícios pela internet talvez merecessem alguma atenção especial.

Mais consoantes à realidade dos fatos, provavelmente estão os casos considerados mais graves e que afetam fortemente o direito de clientes, tais como as infrações relativas à "retenção abusiva de autos", "recusa de prestação de contas" e aquelas classificadas como "prejudicar o cliente por culpa grave".

Como vimos, os processos que chegam ao Tribunal de Ética podem ser subdivididos em dois grandes tipos: aqueles destinados à averiguação de questões relativas à ética profissional, e os que se referem às questões puramente administrativas. Nos processos de natureza administrativa entre os assuntos que apresentam os maiores quantitativos, destacam-se aqueles que são arquivados por serem julgados improcedentes e também os referentes à "inscrição principal", ou seja, aqueles em que o advogado requer o seu credenciamento na ordem.

Conforme a Tabela 3, a seguir, outro tipo de processo de que tem se ocupado muito o TED são os "recursos". Um comparativo entre os anos de 1996 e 2008 demonstra que o número de processos já era significativo em 1996 e que aumentou bastante em 2008. Trata-se, aqui, do recurso, de expediente à disposição de advogados punidos nos processos ou de requerentes insatisfeitos com as decisões das turmas. Os dados demonstram que há um sensível aumento, em termos percentuais, na comparação dos anos 1996 e 2008, sendo que, em 1996, os "recursos" perfaziam um total de 5,8\% do total de processos protocolados, passando para $12,45 \%$ do total em 2008. 
Tabela 3

\begin{tabular}{|c|c|c|c|c|}
\hline $\begin{array}{l}\text { Quantidade por entrada de assunto no TED (sem serem } \\
\text { julgados) }\end{array}$ & $\begin{array}{l}\text { Ano: } \\
1996\end{array}$ & $\begin{array}{l}\text { Total } \\
1996\end{array}$ & $\begin{array}{l}\text { Ano: } \\
2008\end{array}$ & $\begin{array}{l}\text { Total } \\
2008\end{array}$ \\
\hline Abandono de causa ( 1 ) & 31 & 844 & 30 & 815 \\
\hline Advogado empregado & 3 & & - & \\
\hline Advogar contra lei. Imputação indevida de crime & 1 & & 1 & \\
\hline Anuidade, inadimplência & 11 & & 7 & \\
\hline Arquivamento e Improcedência da Representação & 76 & & 135 & \\
\hline Assinatura em Escrito Indevida & 3 & & 1 & \\
\hline $\begin{array}{l}\text { Captação de Causas e de Clientela. Publicidade da Advo- } \\
\text { cacia - Serviços Profissionais }\end{array}$ & 15 & & 19 & \\
\hline Competência & 16 & & 3 & \\
\hline Conduta Incompatível (2) & 56 & & 76 & \\
\hline Consulta: Competência, Honorários & 8 & & 37 & \\
\hline Desídia & 21 & & 8 & \\
\hline Desobediência à OAB & 6 & & 3 & \\
\hline Deturpar o Teor de Dispositivo de Lei & 1 & & 3 & \\
\hline Dever de Urbanidade. & 16 & & 9 & \\
\hline Entendimento com Parte Adversa sem Autorização & 2 & & 4 & \\
\hline $\begin{array}{l}\text { Estagiário - Prática de Atos Privativos de Advogado, } \\
\text { Inscrição Estagiário, Impedimento, Incompatibilidade }\end{array}$ & 72 & & 84 & \\
\hline Exclusão & 7 & & - & \\
\hline Exercício Ilegal da Profissão & 32 & & 18 & \\
\hline Extravio de Autos & 1 & & 1 & \\
\hline Falsa Prova de Requisito de Inscrição & 1 & & 1 & \\
\hline Honorários & 12 & & 15 & \\
\hline Impedimento e incompatibilidade & 22 & & 1 & \\
\hline Imputação Indevida de Crime. & 1 & & 2 & \\
\hline Inépcia profissional. & 9 & & 8 & \\
\hline Inscrição principal & 149 & & 37 & \\
\hline Licenciamento da Advocacia & - & & 8 & \\
\hline
\end{tabular}

Continua... 
Continuação...

\begin{tabular}{|c|c|c|}
\hline Litispendência & 2 & - \\
\hline Mandato & 6 & 8 \\
\hline Patrocínio infiel & 7 & 1 \\
\hline Pedido de Revisão & - & 9 \\
\hline Prejudicar o Cliente por Culpa Grave & 17 & 37 \\
\hline Prerrogativas do Advogado (3) & 60 & 27 \\
\hline Prescrição & 16 & 9 \\
\hline Processo Disciplinar & 25 & 2 \\
\hline Reabilitação & 5 & - \\
\hline $\begin{array}{l}\text { Recebimento de Valores sem Autorização do Cons- } \\
\text { tituinte }\end{array}$ & 1 & 3 \\
\hline Recurso & 49 & 101 \\
\hline Recusa de Prestação de contas & 41 & 47 \\
\hline Retenção abusiva de autos & 40 & 56 \\
\hline Sociedade de Advogados Ilícita & 3 & - \\
\hline Violar Sigilo Profissional & - & 4 \\
\hline Total & 844 & 815 \\
\hline
\end{tabular}

(1) Neste item estão inclusos os casos de abandono de causa por: ausência de provas, desídia, honorários, mandato, prejudicar o cliente por culpa grave, desagravo público.

(2) Neste item estão inclusos os casos de: Concorrer para Ato llegal ou Fraude à Lei, Inidoneidade Moral, Locupletamento, Prática de Crime Infamante, Deveres Éticos do Advogado, Litigância de Má-Fé

(3) Assistência, Pedido de Providência, Contraditório e Ampla Defesa, Desagravo Público, Direito de Ingresso em Dependências e Cartórios, Em Face de Cliente Preso, Em Face de Magistrado, Examinar Processos e Inquéritos, Liberdade de Exercício Profissional, Representação Contra Abuso de Autoridade

Fonte: Departamento de Pesquisa da OAB - RJ: Ementário Digital

A Tabela 4, a seguir, indica as decisões tomadas pelo TED a partir dos processos protocolados. O destaque para esses dados é com respeito ao alto número de arquivamentos: cerca de 49,0\% em 1996, e 47,0\% em 2008. Tais processos, na verdade, julgados improcedentes acabam por ocupar um esforço extraordinário do TED desviando-o significativamente de sua função precípua de "guardião" da ética entre os advogados. 
Tabela 4

\begin{tabular}{l|c|c}
\hline Quantidade por decisões julgadas & $\mathbf{1 9 9 6}$ & $\mathbf{2 0 0 8}$ \\
\hline Arquivamento & 413 & 383 \\
\hline Censura/Advertência & 45 & 55 \\
\hline Suspensão & 51 & 84 \\
\hline Deferido & 184 & 32 \\
\hline Indeferido & 117 & 213 \\
\hline Não compete ao TED & 16 & 33 \\
\hline Remessa ao Conselho Pleno ou retorno ao TED & 3 & 14 \\
\hline Obrigado a prestar contas & 2 & 0 \\
\hline Sugestão de exclusão & 3 & 1 \\
\hline Exclusão & 6 & 0 \\
\hline Desagravo público & 1 & 0 \\
\hline Reabilitação & 1 & 0 \\
\hline Exame de suficiência profissional & 1 & 0 \\
\hline Multa & 1 & 0 \\
\hline Total & $\mathbf{8 4 4}$ & $\mathbf{8 1 5}$ \\
\hline
\end{tabular}

Fonte: Departamento de Pesquisa da OAB - RJ: Ementário Digital

Quanto ao destino dos recursos apostos às decisões das turmas de julgamento do TED, as Tabelas 5 e 6 fornecem algumas importantes informações. Antes, contudo, uma breve explicação. A dinâmica dos recursos pelas partes, advogados e reclamantes, segue o seguinte trâmite no Tribunal: se a decisão das turmas de julgamento foi tomada por maioria dos membros, o recurso próprio disponível para as partes recebe o nome de "Embargo Infringente" e é julgado pelo órgão Pleno do Tribunal de Ética. Se a decisão foi tomada por unanimidade da turma, só cabe recurso ao Pleno do Conselho da OAB. Com respeito aos "Embargos Infringentes" julgados pelo TED protocolados pelos advogados ou pelos requerentes, os resultados, conforme os dados da Tabela 5, foram os seguintes: em 1996, dos 49 recursos protocolados, 40 recursos (cerca de $82 \%$ do total) 
foram indeferidos, 7 foram redefinidos recebendo a punição de censura (cerca de 14\%), 1 recebeu suspensão (2\%) e apenas 1 (2\%) foi enviado à apreciação do Pleno. Em 2008 (Tabela 6), dos 101 recursos protocolados, $82(82 \%)$ foram indeferidos, 16 (16\%) foram deferidos e 3 (3\%) foram remetidos ao Pleno para novo julgamento. Os números sugerem a manutenção de um padrão regular de critérios de julgamento pelos membros do Tribunal, a despeito das diferenças de sua composição.

Tabela 5

\begin{tabular}{|c|c|c|c|c|c|c|c|c|c|c|c|c|c|c|c|c|}
\hline $\begin{array}{c}\text { Tabela } \\
\text { Decisões por Assunto } \\
\text { (Processos Julgados) } \\
-1996\end{array}$ & 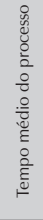 & 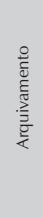 & 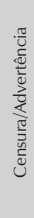 & 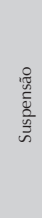 & $\frac{0}{00}$ & $\frac{\frac{0}{0}}{\frac{\pi}{2}}$ & 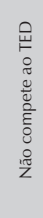 & 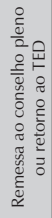 & 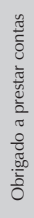 & 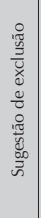 & 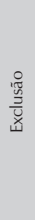 & 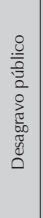 & 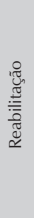 & 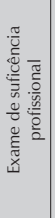 & $\frac{\frac{\pi}{5}}{2}$ & 퓽 \\
\hline Abandono de causa. & 3 & 24 & 5 & 2 & - & - & - & - & - & - & - & - & - & - & - & 31 \\
\hline Advogado Empregado. & 1,6 & - & - & 1 & 2 & - & - & - & - & - & - & - & - & - & - & 3 \\
\hline $\begin{array}{l}\text { Advogar contra lei. } \\
\text { Imputaçãa indevida } \\
\text { de crime. }\end{array}$ & 2 & 1 & - & - & - & - & - & - & - & - & - & - & - & - & - & 1 \\
\hline $\begin{array}{c}\text { Anuidade } \\
\text { (inadimplência) }\end{array}$ & 3,1 & 5 & 1 & 1 & 1 & 3 & - & - & - & - & - & - & - & - & - & 11 \\
\hline $\begin{array}{l}\text { Arquivamento e } \\
\text { improcedência } \\
\text { da representação }\end{array}$ & 2,8 & 71 & - & - & - & - & - & - & - & - & - & - & - & - & - & 71 \\
\hline $\begin{array}{l}\text { Assinatura em Escrito } \\
\text { Indevida. }\end{array}$ & 3 & 2 & 1 & - & - & - & - & - & - & - & - & - & - & - & - & 3 \\
\hline $\begin{array}{l}\text { Captação de Clientela e } \\
\text { Publicidade da Advocacia }\end{array}$ & 1,8 & 12 & 2 & 1 & - & - & - & - & - & - & - & - & - & - & - & 15 \\
\hline Competência. & 1,1 & - & - & - & - & - & 17 & - & - & - & - & - & - & - & - & 17 \\
\hline Conduta incompatível & 3,2 & 32 & 2 & 18 & 1 & 1 & - & - & - & 2 & - & - & - & - & - & 56 \\
\hline Consulta & 0,6 & 10 & - & - & - & 1 & - & - & - & - & - & - & - & - & - & 11 \\
\hline Desídia. & 3,7 & 16 & 3 & 1 & - & - & - & - & - & 1 & - & - & - & - & - & 21 \\
\hline Desobediência à OAB. & 3,7 & 5 & - & 1 & - & - & - & - & - & - & - & - & - & - & - & 6 \\
\hline $\begin{array}{l}\text { Deturpar o Teor de } \\
\text { Dispositivo de Lei. }\end{array}$ & 3 & 1 & - & - & - & - & - & - & - & - & - & - & - & - & - & 1 \\
\hline
\end{tabular}

Continua... 
Continuação...

\begin{tabular}{|c|c|c|c|c|c|c|c|c|c|c|c|c|c|c|c|c|}
\hline Dever de urbanidade. & 2,6 & 12 & 4 & - & - & - & - & - & - & - & - & 1 & - & - & - & 17 \\
\hline $\begin{array}{l}\text { Entendimento com Parte } \\
\text { Adversa sem Autorização. }\end{array}$ & 3,5 & 1 & 1 & - & - & - & - & - & - & - & - & - & - & - & - & 2 \\
\hline Estagiário & 1,2 & 4 & - & - & 49 & 19 & - & - & - & - & - & - & - & - & - & 72 \\
\hline Exclusão. & 7 & 1 & - & - & - & - & - & - & - & - & 5 & - & 1 & - & - & 7 \\
\hline Exercício ilegal da profissão. & 3,9 & 17 & 12 & 1 & - & 1 & - & - & - & - & 1 & - & - & - & - & 32 \\
\hline Extravio de Autos. & 3 & 1 & - & - & - & - & - & - & - & - & - & - & - & - & - & 1 \\
\hline $\begin{array}{c}\text { Falsa Prova de Requisito } \\
\text { de Inscrição. }\end{array}$ & 4 & 1 & - & - & - & - & - & - & - & - & - & - & - & - & - & 1 \\
\hline Honorários. & 2 & 8 & 1 & 3 & - & - & - & - & - & - & - & - & - & - & - & 12 \\
\hline $\begin{array}{l}\text { Impedimento } \\
\text { e incompatibilidade }\end{array}$ & 4,8 & 18 & - & - & 2 & 2 & - & - & - & - & - & - & - & - & - & 22 \\
\hline $\begin{array}{l}\text { Imputação Indevida } \\
\text { de Crime. }\end{array}$ & 5 & 1 & - & - & - & - & - & - & - & - & - & - & - & - & - & 1 \\
\hline Inépcia profissional & 2,3 & 7 & 1 & - & - & - & - & - & - & - & - & - & - & 1 & - & 9 \\
\hline Inscrição principal & 10,4 & - & - & - & 97 & 50 & - & 2 & - & - & - & - & - & - & - & 149 \\
\hline $\begin{array}{l}\text { Licenciamento } \\
\text { da advocacia }\end{array}$ & - & - & - & - & - & - & - & - & - & - & - & - & - & - & - & 0 \\
\hline Litispendência & 7 & 2 & - & - & - & - & - & - & - & - & - & - & - & - & - & 2 \\
\hline Mandato & 3,3 & 5 & 1 & - & - & - & - & - & - & - & - & - & - & - & - & 6 \\
\hline Patrocínio infiel & 2,8 & 6 & - & 1 & - & - & - & - & - & - & - & - & - & - & - & 7 \\
\hline $\begin{array}{l}\text { Prejudicar o Cliente } \\
\text { por Culpa Grave. }\end{array}$ & 2,6 & 12 & 1 & 3 & - & - & - & - & - & - & - & - & - & - & 1 & 17 \\
\hline Prerrogativas do Advogado & 0,9 & 37 & - & - & 23 & - & - & - & - & - & - & - & - & - & - & 60 \\
\hline Prescrição & 5,3 & 13 & - & - & 3 & - & - & - & - & - & - & - & - & - & - & 16 \\
\hline Processo Disciplinar & 2,2 & 22 & 1 & - & 2 & - & - & - & - & - & - & - & - & - & - & 25 \\
\hline Reabilitação & 11,4 & 1 & - & - & 4 & - & - & - & - & - & - & - & - & - & - & 5 \\
\hline $\begin{array}{l}\text { Recebimento de Valores } \\
\text { sem Autorização } \\
\text { do Constituinte. }\end{array}$ & 5 & - & - & 1 & - & - & - & - & - & - & - & - & - & - & - & 1 \\
\hline Recurso & 4,5 & - & - & - & - & 48 & - & 1 & - & - & - & - & - & - & - & 49 \\
\hline Recusa de Prestação de contas & 3,3 & 29 & - & 10 & - & - & - & - & 2 & - & - & - & - & - & - & 41 \\
\hline Retenção abusiva de autos & 2,9 & 32 & 2 & 6 & - & - & - & - & - & - & - & - & - & - & - & 40 \\
\hline Sociedade de Advogados llícita & 2,3 & 3 & - & - & - & - & - & - & - & - & - & - & - & - & - & 3 \\
\hline Violar Sigilo profissional & - & - & - & - & - & - & - & - & - & - & - & - & - & - & - & 0 \\
\hline $\begin{array}{c}\text { Tempo médio total } \\
\text { de duração do processo }\end{array}$ & 3,5 & & & & & & & & & & & & & & & \\
\hline $\begin{array}{l}\text { Número total por tipo } \\
\text { de decisão }\end{array}$ & & 412 & 45 & 51 & 184 & 117 & 16 & 3 & 2 & 3 & 6 & 1 & 1 & 1 & 1 & 844 \\
\hline
\end{tabular}

Fonte: Departamento de Pesquisa da OAB-RJ: Ementário Digital 
Sociologias, Porto Alegre, ano 13, no 28, set./dez. 2011, p. 346-369

Tabela 6

\begin{tabular}{|c|c|c|c|c|c|c|c|c|c|c|c|c|c|c|c|c|}
\hline $\begin{array}{c}\text { Tabela } \\
\text { Decisóes por Assunto } \\
\text { (Processos Julgados) } \\
-1996\end{array}$ & 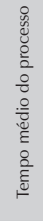 & 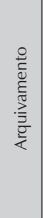 & 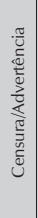 & 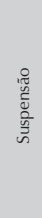 & $\frac{0}{0.0}$ & 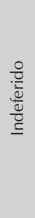 & 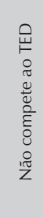 & 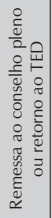 & 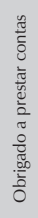 & 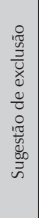 & 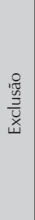 & 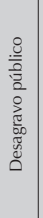 & 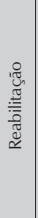 & 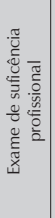 & $\frac{\pi}{3}$ & 丞 \\
\hline Abandono de causa. & 3 & 24 & 5 & 2 & - & - & - & - & - & - & - & - & - & - & - & 31 \\
\hline Advogado Empregado. & 1,6 & - & - & 1 & 2 & - & - & - & - & - & - & - & - & - & - & 3 \\
\hline $\begin{array}{l}\text { Advogar contra lei. } \\
\text { Imputação indevida } \\
\text { de crime. }\end{array}$ & 2 & 1 & - & - & - & - & - & - & - & - & - & - & - & - & - & 1 \\
\hline $\begin{array}{c}\text { Anuidade } \\
\text { (inadimplência) }\end{array}$ & 3,1 & 5 & 1 & 1 & 1 & 3 & - & - & - & - & - & - & - & - & - & 11 \\
\hline $\begin{array}{l}\text { Arquivamento e } \\
\text { improcedência } \\
\text { da representação }\end{array}$ & 2,8 & 71 & - & - & - & - & - & - & - & - & - & - & - & - & - & 71 \\
\hline $\begin{array}{l}\text { Assinatura em Escrito } \\
\text { Indevida. }\end{array}$ & 3 & 2 & 1 & - & - & - & - & - & - & - & - & - & - & - & - & 3 \\
\hline $\begin{array}{l}\text { Captação de Clientela e } \\
\text { Publicidade da Advocacia }\end{array}$ & 1,8 & 12 & 2 & 1 & - & - & - & - & - & - & - & - & - & - & - & 15 \\
\hline Competência. & 1,1 & - & - & - & - & - & 17 & - & - & - & - & - & - & - & - & 17 \\
\hline Conduta incompatível & 3,2 & 32 & 2 & 18 & 1 & 1 & - & - & - & 2 & - & - & - & - & - & 56 \\
\hline Consulta & 0,6 & 10 & - & - & - & 1 & - & - & - & - & - & - & - & - & - & 11 \\
\hline Desídia. & 3,7 & 16 & 3 & 1 & - & - & - & - & - & 1 & - & - & - & - & - & 21 \\
\hline Desobediência à $O A B$. & 3,7 & 5 & - & 1 & - & - & - & - & - & - & - & - & - & - & - & 6 \\
\hline $\begin{array}{l}\text { Deturpar o Teor de } \\
\text { Dispositivo de Lei. }\end{array}$ & 3 & 1 & - & - & - & - & - & - & - & - & - & - & - & - & - & 1 \\
\hline Dever de urbanidade & 3,2 & 8 & - & - & - & - & - & - & - & - & - & - & - & - & - & 9 \\
\hline $\begin{array}{l}\text { Entendimento com Parte } \\
\text { Adversa sem Autorização. }\end{array}$ & 3,8 & 2 & - & 2 & - & - & - & - & - & - & - & - & - & - & - & 4 \\
\hline Estagiário & 2 & - & 2 & - & - & 82 & - & - & - & - & - & - & - & - & - & 84 \\
\hline Exclusão & - & - & - & - & - & - & - & - & - & - & - & - & - & - & - & 0 \\
\hline Exercício llegal da Profissão & 2,6 & 11 & 4 & 3 & - & - & - & - & - & - & - & - & - & - & - & 18 \\
\hline Extravio de Autos & 5 & 1 & - & - & - & - & - & - & - & - & - & - & - & - & - & 1 \\
\hline $\begin{array}{c}\text { Falsa Prova de } \\
\text { Requisito de Inscrição }\end{array}$ & 3 & - & 1 & - & - & - & - & - & - & - & - & - & - & - & - & 1 \\
\hline Honorários & 4 & 14 & - & - & 1 & - & - & - & - & - & - & - & - & - & - & 15 \\
\hline Impedimento & 3 & 1 & - & - & - & - & - & - & - & - & - & - & - & - & - & 1 \\
\hline
\end{tabular}

Continua... 
Continuação...

\begin{tabular}{|c|c|c|c|c|c|c|c|c|c|c|c|c|c|c|c|c|}
\hline $\begin{array}{l}\text { Imputação Indevida de } \\
\text { Crime }\end{array}$ & 1,5 & 2 & - & - & - & - & - & - & - & - & - & - & - & - & - & 2 \\
\hline Inépcia Profissional & 3,3 & 7 & - & 1 & - & - & - & - & - & - & - & - & - & - & - & 8 \\
\hline Inscrição Principal & 7,4 & - & - & - & - & 37 & - & - & - & - & - & - & - & - & - & 37 \\
\hline Licenciamento da Advocacia. & 12,4 & - & - & - & - & 6 & - & 2 & - & - & - & - & - & - & - & 8 \\
\hline Mandato & 2,8 & 4 & 4 & - & - & - & - & - & - & - & - & - & - & - & - & 8 \\
\hline Patrocínio Infiel & 1 & 1 & - & - & - & - & - & - & - & - & - & - & - & - & - & 1 \\
\hline Pedido de Revisão & 5,9 & 2 & - & 7 & - & - & - & - & - & - & - & - & - & - & - & 9 \\
\hline $\begin{array}{l}\text { Prejudicar o Cliente por } \\
\text { Culpa Grave }\end{array}$ & 2,6 & 15 & 16 & 5 & - & - & - & 1 & - & - & - & - & - & - & - & 37 \\
\hline Prerrogativas do Advogado & 1,6 & 20 & - & - & 7 & - & - & - & - & - & - & - & - & - & - & 27 \\
\hline Prescrição & 6,7 & 2 & - & - & 7 & - & - & - & - & - & - & - & - & - & - & 9 \\
\hline Processo Disciplinar & 2,5 & 1 & - & - & 1 & - & - & - & - & - & - & - & - & - & - & 2 \\
\hline Reabilitação & - & - & - & - & - & - & - & - & - & - & - & - & - & - & - & 0 \\
\hline $\begin{array}{l}\text { Recebimento de } \\
\text { Valores sem Autorização do } \\
\text { Constituinte }\end{array}$ & 3,3 & 2 & - & 1 & - & - & - & - & - & - & - & - & - & - & - & 3 \\
\hline Recurso & 3,8 & - & - & - & 16 & 82 & - & 3 & - & - & - & - & - & - & - & 101 \\
\hline $\begin{array}{l}\text { Recusa de Prestação de } \\
\text { Contas }\end{array}$ & 2,9 & 26 & - & 21 & - & - & - & - & - & - & - & - & - & - & - & 47 \\
\hline Rentenção Abusiva de Autos & 2,3 & 39 & 2 & 15 & - & - & - & - & - & - & - & - & - & - & - & 56 \\
\hline $\begin{array}{l}\text { Sociedade de } \\
\text { Advogados Ilícita }\end{array}$ & - & - & - & - & - & - & - & - & - & - & - & - & - & - & - & 0 \\
\hline $\begin{array}{l}\text { Violar Sigilo } \\
\text { Profissional }\end{array}$ & 3,3 & 3 & 1 & - & - & - & - & - & - & - & - & - & - & - & - & 4 \\
\hline $\begin{array}{l}\text { Tempo médio total de } \\
\text { duração do processo }\end{array}$ & 3,3 & & & & & & & & & & & & & & & \\
\hline $\begin{array}{l}\text { Número total } \\
\text { por tipo de decisão }\end{array}$ & & 379 & 55 & 84 & 32 & 213 & 33 & 14 & 0 & 1 & 0 & 0 & 0 & 0 & 0 & 815 \\
\hline
\end{tabular}

Fonte: Departamento de Pesquisa da OAB-RJ: Ementário Digital 


\section{O difícil equilíbrio entre o papel político e o controle profissional: a administração política das punições}

Como é sabido, a Ordem dos Advogados do Brasil teve, e continua a ter, um importante papel no cenário político nacional, e parte de seus esforços nesse campo é o de se manter como uma protagonista no jogo político. Contemporaneamente, esse papel de destaque na política é herança de sua atuação na luta pela redemocratização do país no período da ditadura militar em um contexto de severas restrições à participação dos diversos atores da política nacional.

Sua vocação política se expressa ainda na forma da escolha de seus dirigentes em eleições, com consultas diretas aos seus filiados e ampla repercussão na sociedade em geral, usualmente em campanhas semeIhantes àquelas dos postulantes de cargos de representação política nas assembleias e para os cargos executivos.

No atual contexto de funcionamento pleno das instituições democráticas, no entanto, e com a incorporação de diferentes atores políticos representativos dos diversos grupos sociais, a exemplo dos partidos políticos, sindicatos, organizações não governamentais, igrejas, a atuação política desses agentes ganha contornos muito específicos que restringem a legitimidade de sua representação ao exercício de representações setorizadas, e todos estão submetidos a um rigoroso controle social. No mercado político atual não basta, como no contexto do arbítrio, a coragem e a honradez de lideranças, mas uma bem calculada estratégia e um papel compatível com a relevância social de cada grupo.

Como entidade que persegue a manutenção de seu protagonismo político, a OAB está submetida aos mesmos critérios de inserção no mercado político e só pode fazê-lo na extensão de sua representação classista e prestígio profissional. Ou seja, suas manifestações políticas tendem a ser mais exitosas e mais eficazes nas questões que dizem respeito às críticas 
ao funcionamento do Poder Judiciário, por exemplo, e ao funcionamento dos tribunais e das práticas da magistratura. Críticas às políticas econômicas dos governos tendem a ser menos consideradas pelos outros grupamentos políticos e sociais.

Ao mesmo tempo, a OAB-RJ tem papel regulador da profissão dos advogados com a dupla função de controle e fixação de padrões éticos para o seu exercício, bem como de garantia da manutenção de níveis aceitáveis de conhecimento e qualificação técnica dos advogados. Nessas funções, precisa operar um complexo equilíbrio entre o rigor necessário para manter padrões de qualidade profissional, mas com a medida necessária para evitar exageros que possam levar a resultados iníquos com consequências de deslegitimação de seu papel regulador junto aos profissionais.

Tem, assim, a Ordem dos Advogados um trabalho de construção das bases de sua legitimidade para a ação política que tem que repercutir duplamente, para dentro e para fora. Para dentro, no sentido de que sua existência como entidade classista e suas fortes prerrogativas de controle profissional só podem persistir no tempo se ela consegue o respeito junto aos seus filiados para os seus critérios de credenciamento. Para fora, a sua legitimidade para cobrar das demais instituições políticas comportamento moralizante e equânime depende do reconhecimento público de sua atuação na fiscalização do comportamento e desempenho profissional de seus filiados.

Dadas essas características da $\mathrm{OAB}$, de sua dupla natureza política e profissional, o Tribunal de Ética da instituição figura como um órgão crucial. Sua atuação e o seu desempenho são fundamentais para a construção das bases da legitimidade para dentro e para fora, as quais nos referimos anteriormente. Por um lado, seu poder de impor sanções reaviva nas consciências de seus profissionais a necessidade de atuar segundo regras de comportamento da ética profissional definida pela entidade. Ao mesmo tempo, essa atuação repercute e reforça na sociedade o sentimento 
de que a entidade está cumprindo o seu dever de garantir a qualidade técnica e de punir os maus profissionais. Eis as razões da centralidade do TED na estrutura da OAB.

Essa percepção não escapa aos dirigentes da instituição e nem mesmo aos funcionários do Tribunal. Um de seus funcionários expressou da seguinte maneira a consciência dessa situação:

A cobrança dos reclamantes é constante e ameaçam ir à mídia quando o processo demora muito e sentem-se prejudicados por conta disso. A cobrança torna-se mais intensa também quando a questão financeira está presente. Não que o Tribunal de Ética vá proporcionar algum ressarcimento, mas, após a finalização do processo, a pessoa lesada pode entrar na justiça reclamando por dano moral e etc., anexando a decisão do Tribunal.

A questão da "moralização" dos profissionais da OAB também conta. Como cobrar do sistema judiciário que seja idôneo e ágil se os próprios Tribunais da OAB também não forem?

\section{Conclusão}

Nessas considerações finais, gostaríamos de dar destaque a algumas questões que foram trabalhadas neste artigo. Primeiramente, elucidamos que esta pesquisa não pretendeu dar conta da análise de todas as infrações cometidas pelo grupo profissional que estamos estudando. Como enfatizamos, os dados analisados representam apenas os processos que foram protocolados no Tribunal de Ética da OAB-RJ, ou seja, isso não significa necessariamente que todas as pessoas, sejam clientes, advogados, juízes e outros, que se sentiram prejudicados por determinada infração ética, tenham recorrido a essa instituição (ao TED).

Procuramos evidenciar com nosso trabalho o papel que o Tribunal de Ética e Disciplina progressivamente passou a assumir, tanto interna- 
mente em relação à própria $\mathrm{OAB}$, quanto para toda a categoria profissional que representa. O papel político que a OAB pretende conquistar e o monopólio do credenciamento profissional que ela pretende manter dependem de um funcionamento criterioso e eficiente do TED.

Em parte por essas avultadas responsabilidades, o Tribunal de Ética e Disciplina da $\mathrm{OAB}$, principalmente a partir da promulgação do Novo Código de Ética, passou a ampliar o escopo de sua atuação e, em nossa pesquisa, pudemos perceber a grande variedade de temas que cada vez mais adentram, neste Tribunal, através da sua Secretaria. São assuntos dos mais variados tipos, que vão desde a tentativa de isenção de anuidade, até temas de cunho ético mais grave, como a retenção pecuniária dos clientes ou o envolvimento de profissionais da advocacia com o tráfico de drogas.

Um aspecto importante que talvez mereça mais consideração de seus membros e dos conselhos superiores da OAB talvez seja a ampliação da capacidade de julgamento do TED, por conta das demandas crescentes. Por tudo que pudemos acompanhar, o futuro da própria OAB depende de uma especial atenção ao funcionamento do TED.

\section{Profession and corporation: ethical limits to a lawyer's activity}

\section{Abstract}

This paper analyzes the performance of the Ethics and Disciplinary Court of Rio de Janeiro state Bar Association (OAB-RJ) from two perspectives: the first is based on a qualitative analysis of the most frequent lawyer misconduct committed in his/her professional activities and outlines an analysis of the administration of punishment by Members of the Court. The second perspective seeks to assess this Court within the internal organizational structure of $O A B$ and its role in legitimizing the political participation of the entity. Therefore, we analyzed the difficult task of achieving a balance between the representational activities of the Bar Association and its political role.

Keywords: Sociology of professions. Professional ethics. Lawyers. Court of ethics. 


\section{Referências}

ALEMÃO, Ivan. OAB e sindicatos. São Paulo: LTr, 2009.

BARBOSA, Evandro Paes. Ética entre advogados e clientes. Anais XVIII Conferência Nacional dos Advogados: cidadania, ética e Estado. Brasília: OAB, Conselho Federal, 2002.

CICOUREL, Aaron V. Police Practices and Offial Records. In: The Social Organization of Juvenile Justice. Wiley: 1968. p 112-123.

COCCARO, Celso. Processo Disciplinar. In: MACEDO JUNIOR, Marco Antônio Silva de; COCCARO, Celso. Ética profissional e Estatuto da Advocacia. São Paulo: Saraiva, 2009.

GUIMARÃES, Paulo F. Torres (Org.). Estatuto da Advocacia e da OAB e legislação complementar. 6a Ed., Brasília: OAB, Conselho Federal, 2007.

LÔBO, Paulo Luiz Netto. Comentários ao estatuto da Advocacia e da OAB. São Paulo: Saraiva, 2009.

NALINI, José Renato. A ética nas profissões jurídicas. In: FARAH, Elias (Org.). Ética do Advogado. São Paulo: LTr, 2000.

Recebido em: 05/05/2011

Aceite final: 12/08/2011 